\title{
Impacto y manejo de las dermatosis exudativas
}

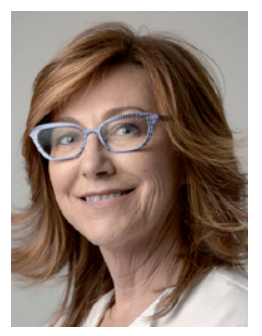

Esther Jiménez Blázquez

Facultativo especialista de área de dermatología.

Hospital Universitario

de Guadalajara.

Profesora asociada de Dermatología. Universidad de Alcalá de Henares (Madrid).

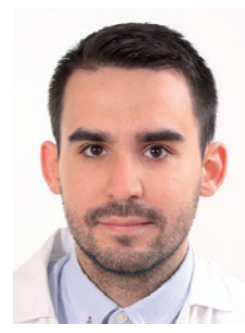

\section{Iván Checa Recio}

Facultativo especialista de área de dermatología. Hospital Universitario de Guadalajara.

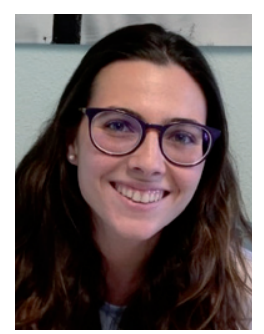

M. ㄹ Elena Sánchez-Migallón Jiménez Residente de tercer año de medicina familiar y comunitaria. Centro de Salud Guadalajara Sur. Hospital Universitario de Guadalajara.

\section{RESUMEN}

El término dermatosis exudativas hace referencia a aquellos procesos dermatológicos que cursan con lesiones cutáneas que presentan exudación. Se encuadran dentro de las dermatosis agudas y se caracterizan por la presencia de edema, eritema, vesiculación y exudación. Son muchas las enfermedades cutáneas de distinta etiología que pueden presentarse clínicamente como dermatosis exudativa, destacando por su frecuencia: el eccema agudo, el impétigo, las infecciones víricas por el virus del herpes simple y el virus de la varicela-zóster, la tiña de los pies, el intertrigo o las picaduras. Las dermatosis exudativas son lesiones húmedas y su manejo requiere dos tipos de actuaciones: una primera actuación dirigida a disminuir la exudación y otra enfocada al tratamiento específico de la enfermedad.

Palabras clave: dermatosis, exudación, compresas húmedas.

\section{SUMMARY}

The term exudative dermatosis refers to those dermatologic diseases that happen with skin lesions that produce exudation. They are included in the acute dermatosis and they characteristically present with swelling, erythema, vesiculation and exudation. There are many skin diseases with diverse etiologies that can clinically present as exudative dermatosis. We highlight by its frequency: acute eczema, impetigo, viral infections by herpes simplex virus and varicella-zoster virus, tinea pedis, intertrigo and bites. Exudative dermatosis are wet skin lesions and their management requires two types of interventions: first, to decrease the exudation, and second, the specific treatment of the disease.

Key words: dermatosis, exudation, wet dressings. 
Dermatosis es un término que se utiliza para definir de forma genérica las alteraciones en la piel. Se trata de procesos frecuentes de múltiple causa y formas clínicas variadas, que pueden ir desde lesiones secas y descamativas a lesiones exudativas, vesiculoampollosas, costrosas o erosivoulcerosas. El término dermatosis exudativas hace referencia a aquellos procesos dermatológicos que cursan con lesiones cutáneas que presentan exudación; se definen como «lesiones húmedas» por su aspecto clínico y son muchas las enfermedades inflamatorias cutáneas que pueden presentar esta forma clínica.

Según el momento evolutivo, las dermatosis se clasifican en distintas fases: aguda, subaguda y crónica. Las dermatosis exudativas corresponden a lesiones en fase aguda y se caracterizan por la presencia de edema, eritema, vesiculación y exudación. Cuando la inflamación y el eritema van siendo menos intensos y desaparecen la vesiculación y la exudación, nos encontramos en la fase subaguda. En la fase crónica, ha disminuido la inflamación y el eritema y las lesiones son secas, con descamación, liquenificación y cambios en la pigmentación ${ }^{1}$ (tabla 1).

\section{FISIOPATOLOGÍA}

Los procesos inflamatorios que ocurren en la dermis a nivel de la unidad de tejido conectivo-plexo vascular superficial generan una activación endo- telial con dilatación vascular, aumento de la permeabilidad, edema, acumulación de eritrocitos en las asas capilares e infiltración celular del tejido perivascular. Esta alteración de la permeabilidad de los pequeños vasos sanguíneos en el área de la lesión permite el escape de líquido, proteínas y células sanguíneas desde los sistemas vasculares al tejido intersticial que se conoce como exudación (fig. 1-a). Un exudado es un líquido extravascular inflamatorio que tiene una alta concentración de proteínas y restos celulares. Existen distintos tipos de exudados, dependiendo de la cantidad de proteínas y/o células que contengan: el exudado seroso, con un contenido proteico relativamente bajo y con muy pocas células; el exudado fibrinógeno, rico en proteínas; y el exudado purulento, rico en neutrófilos.

La pérdida de proteínas desde el plasma reduce la presión osmótica intravascular y aumenta la presión osmótica en el líquido intersticial. Junto con el aumento de la presión hidrostática debido al incremento del flujo vascular a través de los vasos dilatados, se produce un flujo marcado de salida de líquido y su acumulación en el tejido intersticial. El aumento neto de líquido extravascular da lugar al edema². El líquido procedente de la extravasación de los vasos sanguíneos del plexo de la dermis superficial por gradiente osmótico o por presión hidrostática puede extenderse desde la dermis hacia el compartimento intercelular de la epidermis, separando los queratinocitos y pro-

Tabla 1. Fases de las dermatosis

\begin{tabular}{l|l|l}
\hline Fases & Características & Tratamiento \\
\hline Aguda & $\begin{array}{l}\text { Edema, eritema } \\
\text { Vesículas } \\
\text { Exudación }\end{array}$ & $\begin{array}{l}\text { Soluciones, lociones, emulsiones, } \\
\text { cremas }\end{array}$ \\
\hline Subaguda & $\begin{array}{l}\text { Mínimo edema } \\
\text { Eritema } \\
\text { Descamación }\end{array}$ & Cremas \\
\hline Crónica & $\begin{array}{l}\text { Xerosis, descamación, liquenificación, } \\
\text { cambios en la pigmentación }\end{array}$ & Pomadas, ungüentos \\
\hline
\end{tabular}




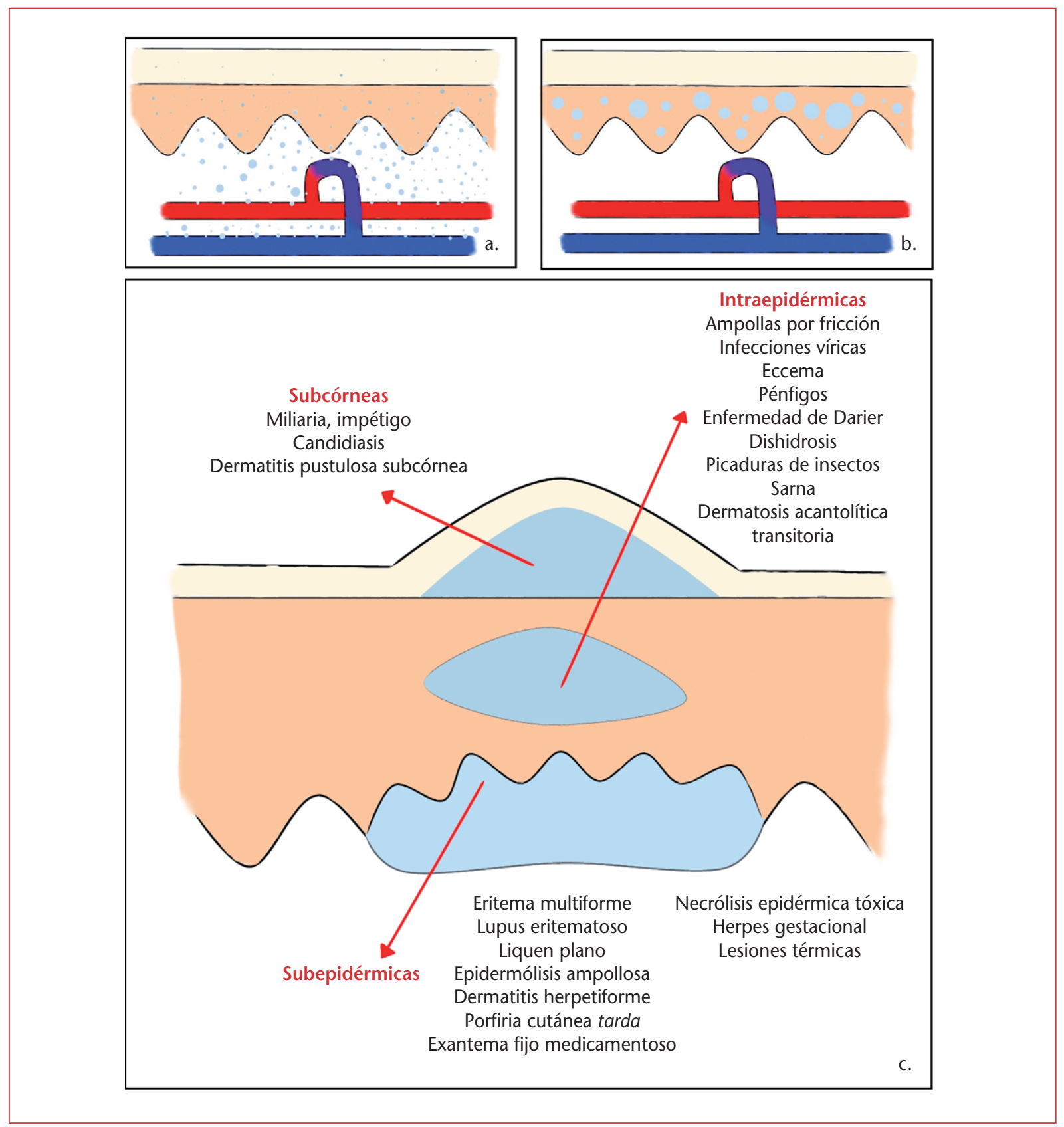

Figura 1. a. Difusión desde el plexo vascular a la epidermis. b. Espongiosis. c. Enfermedades vesiculoampollosas.

duciendo una alteración de la cohesión epidérmica denominada espongiosis (fig. 1-b) y la formación de una pequeña cavidad ocupada por líquido o vesícula intraepidérmica. También el líquido procedente de la dermis puede llegar a la epider- mis cuando la alteración de la cohesión celular se produce de forma primaria por alteración de las uniones intercelulares (acantólisis) en enfermedades de origen autoinmunitario como los pénfigos, alteraciones genéticas como la enfermedad 
de Darier o enfermedades víricas. En estas circunstancias, se crean cavidades llenas de líquido (ampollas) que pueden situarse a distintos niveles de la epidermis. Muchas enfermedades cutáneas de muy diversa etiología van a presentar clínicamente microvesículas, vesículas o ampollas que contienen un exudado seroso, serohemorrágico o pustuloso y cuya rotura provocará la aparición de procesos exudativos $^{3}$ (fig. 1-c). Otras dermatosis de naturaleza no exudativa pueden hacerse exudativas de forma secundaria si sufren episodios intercurrentes de infección, eccematización o erosión. La infección —sobre todo, la impetiginización- es un fenómeno frecuente debido a la pérdida de integridad de la piel enferma, al rascado o a la falta de higiene o de un tratamiento adecuado. Muchas lesiones cutáneas (nevos, molusco) pueden sufrir una eccematización secundaria por irritación o de forma espontánea en pacientes con antecedentes atópicos. Además, la aparición de erosión, fisuración o ulceración de una lesión por traumatismos (rascado, roce...) o por necrosis tisular (tumores, úlceras...) puede inducir el desarrollo de una exudación secundaria.

Por lo tanto, el impacto de este tipo de dermatosis es muy relevante por la cantidad de patología implicada, el volumen de consultas que puede generar y la necesidad de un manejo específico adecuado.

\section{DERMATOSIS EXUDATIVAS FRECUENTES}

A pesar de la gran variedad de procesos que pueden comportarse en algún momento de su evolución como dermatosis exudativas, destacan por su alta prevalencia en la población: el eccema agudo, el impétigo, las infecciones víricas por el virus del herpes simple (VHS) y el virus de la varicela-zóster (VVZ), la tiña de los pies, el intertrigo o las picaduras.

\section{Eccema agudo}

La dermatosis exudativa más representativa y frecuente es el eccema en su fase aguda. El eccema es una reacción inflamatoria cutánea en la que se suceden una serie de lesiones elementales, que van desde el eritema y edema muy pruriginoso a la aparición de vesículas que evolucionan hacia costras, descamación y liquenificación. Los diferentes tipos de eccema representan un tercio de las consultas dermatológicas. Se pueden distinguir, por un lado, dos grandes grupos: la dermatitis atópica y los eccemas de contacto; $y$, por otra parte, otros tipos de eccema como el dishidrótico, el numular, el de estasis, el asteatósico, el liquen simple crónico, los eccemas fotoinducidos o los producidos por sensibilización.

En la dermatitis atópica, las formas más exudativas suelen verse en la fase de lactante (3 meses- 2 años) y afectando preferentemente a las mejillas, el cuero cabelludo y los pliegues. En la fase infantil, se localizan, sobre todo, en las flexuras de los pliegues antecubitales y retropoplíteos y suelen ser formas subagudas con menos exudación. En los adultos, se describen presentaciones subagudas y crónicas, aunque, en ocasiones, pueden desarrollar episodios de lesiones agudas exudativas. Se ha demostrado que Staphylococcus aureus puede ser aislado en el $70 \%$ de las lesiones de eccema ${ }^{4}$, favoreciendo la aparición de exudación por impetiginización secundaria. Los eccemas de contacto son dermatitis provocadas por un agente exógeno (irritante o alérgeno). Las formas irritativas pueden ser agudas o crónicas. Las agudas son exudativas y se suelen relacionar con agentes irritantes potentes. Las crónicas se asocian a la exposición repetida a productos irritantes menos potentes como los jabones o el agua, y van a ocasionar formas clínicas con descamación y liquenificación, en vez de lesiones exudativas. La dermatitis de contacto alérgica representa una reacción de hipersensibilidad retardada de tipo IV, que precisa una sensibilización previa al producto responsable (fig. 2). Clínicamente, debido a la intensa espongiosis provocada por la respuesta inflamatoria inmunitaria, suelen dar formas agudas con reacciones exudativas localizadas en las áreas donde el alérgeno ha contactado, aunque, dependiendo de la concentración del alérgeno, el tiempo de expo- 


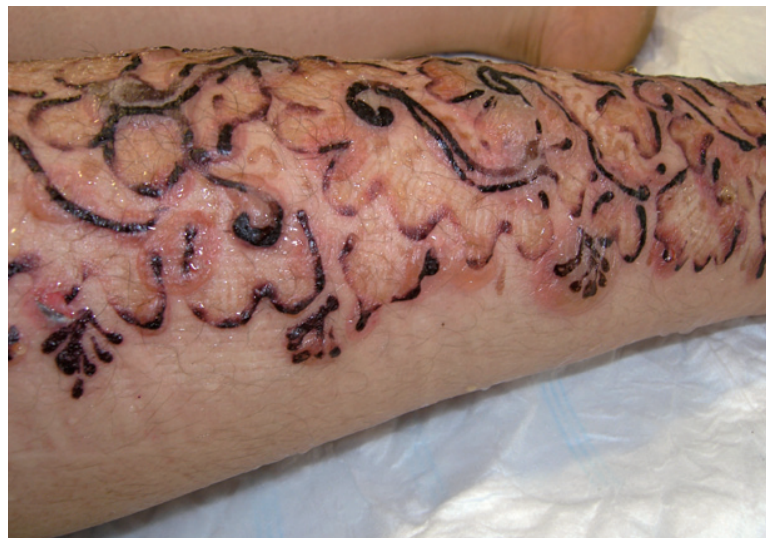

Figura 2. Eccema agudo de contacto por tatuaje.

sición o el grado de sensibilización y respuesta inflamatoria del paciente, pueden observarse reacciones subagudas o crónicas.

Del resto de eccemas, preferentemente, los eccemas dishidróticos son los que presentan lesiones con un carácter intensamente exudativo. Esta dermatosis de etiología incierta, en la que se han implicado distintos factores, presenta brotes recurrentes de vesículas que afectan a las manos y/o los pies y, especialmente, a los bordes laterales de los dedos, y pueden confluir formando ampollas de mayor tamaño. Además, la localización interdigital predispone a la humedad, que agrava el aspecto exudativo de las lesiones. Las dermatitis de estasis son lesiones eccematosas relacionadas con la insuficiencia venosa de larga evolución; aparecen en las extremidades inferiores y en la piel perilesional de las úlceras venosas (fig. 3). Clínicamente, son eccemas agudos de carácter exudativo que suelen reagudizarse por infección y/o sensibilización secundaria al uso de múltiples cremas y, en ocasiones, se diseminan por un fenómeno de autosensibilización. Mínimos traumatismos condicionan erosiones y aparición de úlceras que pueden agravar la exudación ${ }^{5}$. Los eccemas numulares son placas redondeadas que afectan, sobre todo, a las extremidades y al tronco relacionadas con factores irritativos, xerosis y predisposición atópica. Pueden tener componente exudativo, con pequeñas vesículas que se rompen generando

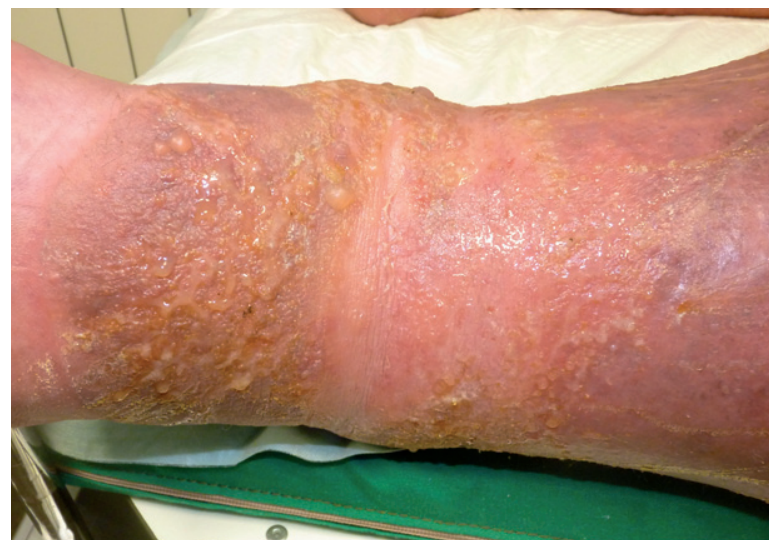

Figura 3. Eccema de estasis.

costras de material seroso, y no es raro que se sume una impetiginización secundaria que incrementa este componente de lesión húmeda. Sin embargo, otros eccemas como el eccema asteatósico o el liquen simple crónico se comportan como dermatitis en fase subaguda y crónica en las que predominan la descamación y la liquenificación.

\section{Infecciones}

Las infecciones bacterianas constituyen el $20 \%$ de las consultas dermatológicas, siendo los estafilococos y los estreptococos los gérmenes más frecuentemente implicados. Producen cuadros clínicos que van desde el impétigo o la celulitis a formas graves de afectación multisistémica como el síndrome de shock tóxico. El impétigo es una de las dermatosis infecciosas típicamente exudativa; es muy frecuente y especialmente prevalente en los niños. Actualmente, el patógeno más aislado es el estafilococo. El impétigo ampolloso comienza con pequeñas vesículas, que se convierten en ampollas flácidas con contenido claro, que después se hace purulento. El techo de la ampolla se rompe fácilmente, dejando una mácula eritematosa brillante y húmeda. Ocurre más frecuentemente en áreas intertriginosas. El impétigo no ampolloso (costroso) representa más del $70 \%$ de todos los casos de impétigo. Ocurre en adultos y niños, pero es raro en niños menores de 2 años (fig. 4). En las tres últimas décadas, Staphylococcus aureus es res- 


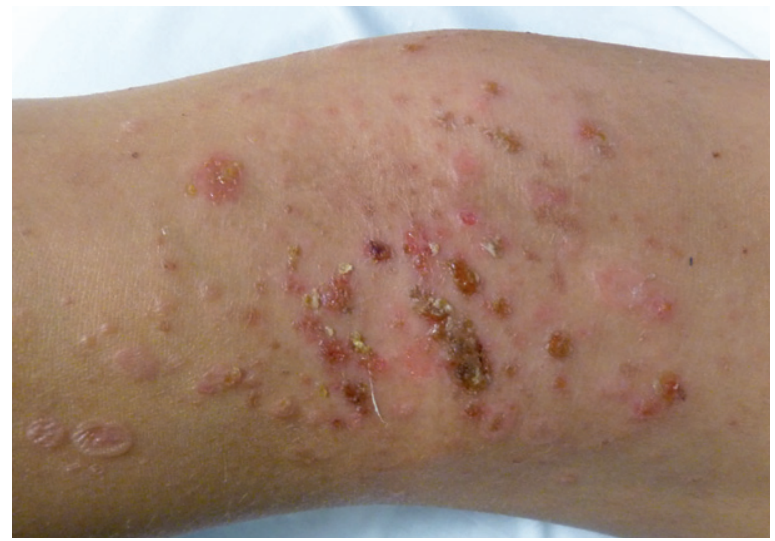

Figura 4. Impétigo.

ponsable del $80 \%$ de los casos, solo o en combinación con el estreptococo betahemolítico del grupo A. El impétigo costroso puede ocurrir en piel normal o sobre una dermatosis previa. La malnutrición y las malas condiciones higiénicas son factores predisponentes. La lesión inicial es una vesícula sobre una base eritematosa, que se rompe fácilmente, dando lugar a una ulceración superficial cubierta de exudado, que se seca formando costras amarillentas adherentes (melicéricas). Predomina en áreas expuestas, especialmente, en la cara y las extremidades ${ }^{6}$.

Las infecciones víricas de mayor incidencia son las producidas por el VHS (herpes simple y genital) y VVZ (varicela y herpes zóster). Característicamente, provocan edema del citoplasma por acumulación de agua (balonización) y pérdida de los puentes intercelulares, que ocasiona la aparición de vesículas intraepidérmicas. Clínicamente, observaremos la presencia de ampollas agrupadas en localizaciones características (oral o genital en la infección por el VHS o con distribución metamérica en la infección por el VVZ) (fig. 5), excepto en la varicela, en la que se disponen de forma dispersa. De modo más excepcional, pero con expresión clínica muy exudativa, puede aparecer un cuadro denominado eccema herpeticum, producido por diseminación de la infección por el VHS en áreas de piel previamente alteradas por otros procesos dermatológicos, sobre todo, en pacientes con

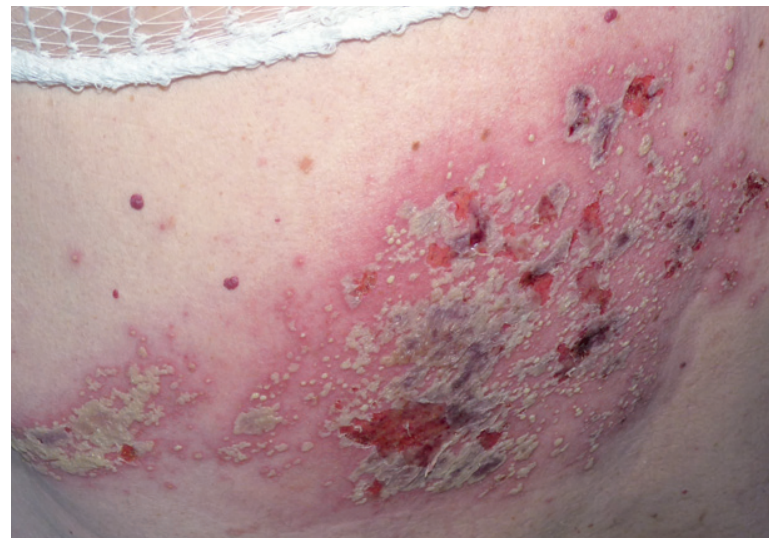

Figura 5. Herpes zóster.

lesiones de dermatitis atópica. Otros virus, como el virus Coxsackie y Enterovirus producen también cuadros vesiculoampollosos palmoplantares acompañados de estomatitis aftosa con frecuencia en la infancia.

Las infecciones cutáneas por hongos son un importante motivo de consulta. La pitiriasis versicolor, las tiñas y las candidiasis representan prácticamente la mayoría de las infecciones micóticas en nuestro medio. Todas las tiñas pueden presentar distintos grados de exudación según su localización y componente agudo inflamatorio. La tiña de los pies se considera la más frecuente a nivel mundial. Puede presentar distintas formas clínicas: una crónica, con lesiones secas, denominada hiperqueratósica o «en mocasín»; y dos de carácter exudativo: la dishidrosiforme, con lesiones vesiculoampollosas, y la forma interdigital, con maceración, fisuras y descamación. Esta última es la más frecuente y la de presentación clínica más exudativa. La predisposición genética, la oclusión del calzado, la sudoración y los ambientes húmedos favorecen su aparición. Suele afectar al espacio entre el cuarto y el quinto dedos, pero puede extenderse al resto de los espacios interdigitales y afectar a las uñas y al resto del pie. En general, desarrolla un aspecto fisurado húmedo y exudativo, al que con frecuencia se une una sobreinfección bacteriana que agrava el aspecto exudativo. Las cándidas necesitan humedad y maceración, por lo que las zo- 
nas cutáneas más afectadas en la piel van a ser los pliegues, ocasionando el intertrigo candidiásico.

\section{Intertrigo}

El intertrigo es una dermatosis inflamatoria que afecta a los pliegues del cuerpo y se ve favorecido por la fricción y la humedad. Se observa, sobre todo, en los grandes pliegues (submamario, inguinal...), pero puede afectar a pequeños pliegues como los interdigitales. La piel dañada puede ser secundariamente infectada por bacterias u hongos. Se presenta como un eritema simétrico de aspecto húmedo con picor y escozor. En el fondo del pliegue, puede observarse una fisura que rezuma líquido seroso (fig. 6). Este proceso inflamatorio se ve facilitado por el calor, la obesidad y la sudoración. Algunas dermatosis que se localizan en pliegues como la psoriasis, la dermatitis seborreica o la tiña crural pueden presentar componente exudativo y requerir diagnóstico diferencial. La colonización candidiásica es frecuente, apareciendo un borde con collarete descamativo y lesiones satélites en forma de pequeñas pústulas salpicadas, que se rompen, intensificando el aspecto exudativo. La dermatitis irritativa del área del pañal se produce por las condiciones de humedad, maceración, fricción y contacto con la orina y las heces en la zona cubierta por el pañal. Tiene una alta

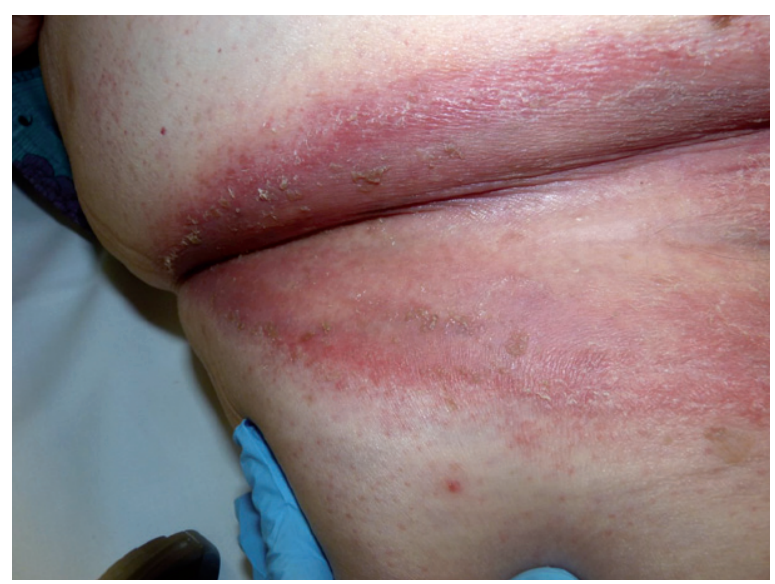

Figura 6. Intertrigo. prevalencia y la sobreinfección por cándidas también es frecuente.

\section{Picaduras}

Entre las dermatosis que afectan frecuentemente al ser humano, se encuentran las picaduras de artrópodos. Causan reacciones cutáneas de morfología variada y, aunque, en general, suelen presentarse como pápulas urticariformes, con frecuencia, desarrollan una pequeña vesícula de contenido claro o hemorrágico que acaba dando lugar a costras serohemáticas. La formación de ampollas es más frecuente en los niños y suelen localizarse en las piernas ${ }^{7}$. El componente exudativo de estas lesiones puede intensificarse por impetiginización secundaria, sobre todo, debido al rascado.

Otras lesiones exudativas frecuentes son las úlceras de las piernas. La mayoría son secundarias a insuficiencia venosa. La difusión desde los capilares de líquido e, incluso, fibrina predispone a la aparición de dermatitis exudativas y úlceras, que drenan un exudado seroso. El proceso se perpetúa por el edema crónico y la infección secundaria. Aunque las toxicodermias representan un porcentaje considerable de la patología dermatológica, suelen presentarse como erupciones maculopapulosas. Ocasionalmente, adquieren formas exudativas como el exantema fijo, el eritema multiforme, las dermatosis neutrofílicas, pustulosas o ampollosas, las paroniquias por quimioterápicos, etc.

Las dermatitis exudativas más frecuentes en la infancia son la dermatitis atópica, el impétigo, el herpes simple, la dermatitis irritativa del pañal y la enfermedad de manos, pies y boca. Menos frecuentes son el eccema herpeticum y las enfermedades ampollosas como el penfigoide o las dermatosis por inmunoglobulina A infantiles. En los pacientes de mayor edad, serán, sobre todo, el intertrigo y las lesiones relacionadas con la insuficiencia venosa y, con menor frecuencia, las enfermedades ampollosas, especialmente, el penfigoide ampolloso.

Topográficamente, las lesiones exudativas más habituales en la cara suelen ser la dermatitis ató- 
pica, el eccema de contacto y las infecciones como el herpes y el impétigo. En el tronco, las lesiones vesiculosas del herpes zóster, los eccemas de contacto o numulares y algunos exantemas medicamentosos o enfermedades ampollosas autoinmunitarias. En los pliegues, sin duda, el intertrigo y el intertrigo candidiásico. Otras son la tiña crural o la psoriasis de los pliegues. En localizaciones palmoplantares, sobre todo, el eccema dishidrótico, la tiña de los pies o las pustulosis palmoplantares. Y en las extremidades, el eccema numular o las picaduras, la dermatitis de estasis y las úlceras venosas.

En resumen, una amplia gama de procesos dermatológicos de toda índole puede presentarse como dermatosis exudativas en algún momento de su evolución. De forma primaria, porque sean procesos en los que la inflamación ocasiona la aparición de exudación, o secundariamente, porque se impetiginizan, se eccematizan o se ulceran.

\section{MANEJO DE LAS DERMATOSIS EXUDATIVAS}

En la toma de decisiones terapéuticas, es útil la clasificación de las dermatosis en agudas, subagudas y crónicas (tabla 1). En general, podemos decir que, para las dermatitis agudas, se prefiere el uso de líquidos, fomentos y polvos; en las subagudas, cremas y, en las dermatitis crónicas, pomadas y ungüentos para favorecer la rehidratación de la $\mathrm{piel}^{8}$. Las dermatosis exudativas son lesiones húmedas que se encuadran en el grupo de las dermatosis agudas y su abordaje requiere dos tipos de actuaciones: una primera actuación dirigida a disminuir la exudación («secar la lesión») y otra enfocada al tratamiento específico o etiológico de la enfermedad.

En los tratamientos tópicos, el excipiente se escoge en función del grado de humedad e inflamación de la lesión, mientras que la enfermedad determina la elección del principio activo ${ }^{9}$. Las lesiones muy inflamadas van a presentar humedad y exudación, que controlaremos mediante la realización de un tratamiento secante. El excipiente más adecuado en estas lesiones son las soluciones; suelen aplicarse en forma de fomentos o compresas húmedas en cura abierta o en forma de toques, pincelaciones, baños o nebulizaciones. Sus propiedades fundamentales radican en que, al evaporarse, producen vasoconstricción por enfriamiento, induciendo un efecto antiinflamatorio y secante. Eliminan exudados, costras y detritos, y ayudan a mantener la limpieza de las zonas infectadas $^{9}$. Las compresas deben ser de tejido limpio y suave, de cuatro a ocho capas y de tamaño solo un poco mayor que la zona a tratar para evitar la maceración del contorno perilesional. Deben estar empapadas en el líquido, pero sin gotear. Una vez aplicadas sobre la lesión, no se recomienda humedecerlas de forma repetida. Si es preciso, es mejor usar una nueva para evitar aumentar la concentración de la solución ${ }^{10}$. Se aplican durante 15-30 minutos tres o cuatro veces al día. La temperatura de la compresa debe ser fría cuando se busca un efecto antiinflamatorio, y tibia cuando se busca desbridar una lesión costrosa. Cubrir las compresas con plástico (cura cerrada) promueve la maceración e incrementa la temperatura de la piel, lo cual facilitaría el crecimiento bacteriano. Una vez que la fase húmeda de la enfermedad ha sido controlada, deberían suspenderse para evitar causar agrietamiento y fisuras, y utilizar cremas emolientes y lociones para restituir los lípidos de la piel. Las compresas húmedas aportan una acción antibacteriana gracias a las propiedades antisépticas de los elementos que se añaden a la solución, favorecen el desbridamiento de los exudados al retirarlas, tienen acción antiinflamatoria por enfriamiento y vasoconstricción y, además, una acción secante.

Hay que tener en cuenta que podemos correr algunos riesgos si no se utilizan en la forma o concentración adecuadas. En ocasiones, estos principios activos son preparados por el paciente y pueden ocurrir errores. Los preparados que ya vienen diluidos y con indicaciones de uso detalladas van a ser más seguros. Distintas formulaciones magistrales con soluciones acuosas y pastas se detallan en la tabla 2. 
Tabla 2. Fórmulas magistrales: soluciones acuosas y pastas

\begin{tabular}{|c|c|}
\hline Soluciones acuosas & Pastas \\
\hline 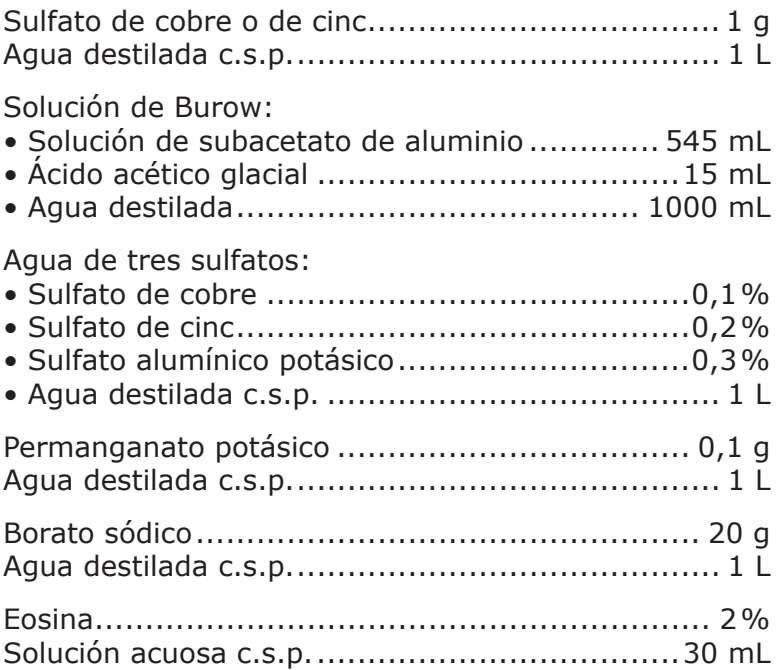 & 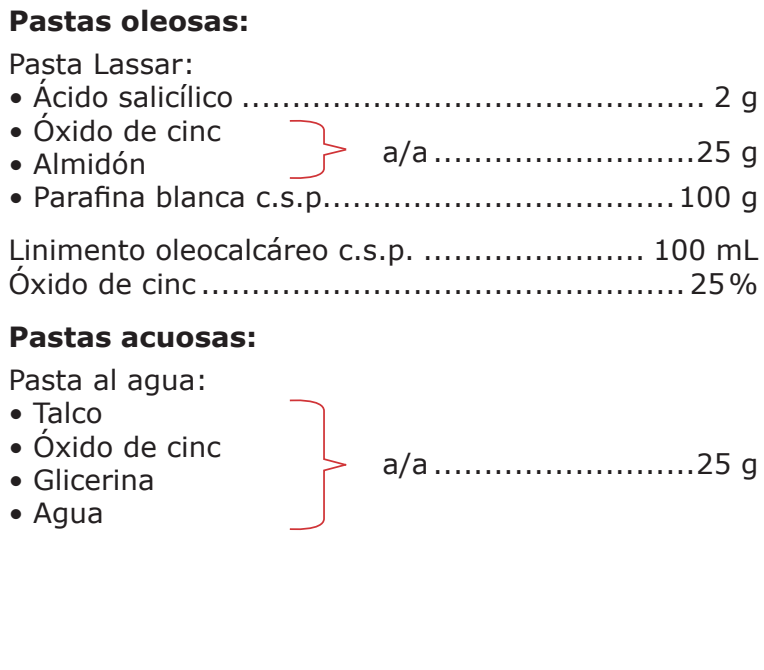 \\
\hline
\end{tabular}

a/a: a partes iguales; c.s.p.: cantidad suficiente para.

Los fomentos con sulfato de cinc y/o cobre son los más utilizados en la práctica diaria actual. En bajas concentraciones $(1: 1000)$ producen una acción astringente. El uso de las sales de cinc tópicas tiene un potencial microbicida frente a las infecciones herpéticas ${ }^{11}$. También son conocidas las propiedades antimicrobianas del cobre como germicida y fungicida, y se ha demostrado una actividad antimicrobiana sinérgica del sulfato de cinc y cobre en formulaciones tópicas ${ }^{12}$. Las altas concentraciones pueden inhibir la epitelización y aumentar la inflamación, por lo que deben usarse solo en las concentraciones recomendadas. La «solución de tres sulfatos» combina sulfato de cinc, de cobre y de aluminio para potenciar su acción. $\mathrm{El}$ ácido bórico al $2 \%$ tiene una acción predominantemente antifúngica, se comporta como un fungistático y, en diluciones acuosas, aumenta su poder bacteriostático. Es interesante en las lesiones húmedas donde haya riesgo de infección por cándidas. El permanganato potásico es astringente y tiene acción antimicrobiana de amplio espectro, pero presenta el inconveniente de producir una coloración marronácea de la piel y de las uñas. Es esencial que la solución que se prepare no sea demasiado fuerte y que, al usarse, no contenga cristales sin disolver, dado que podrían causar ulceración ${ }^{13}$. Para evitar la irritación, se recomienda su uso a bajas concentraciones, habitualmente, 1:10 000. La solución de eosina al $\mathbf{2 \%}$ en agua es antiséptica y secante, se ha recomendado en las dermatitis del pañal erosivas ${ }^{14}$. Una solución clásica descrita en los formularios es la «solución de Burow», tiene un fuerte carácter astringente, por lo que se aplica diluida a un tercio o a un cuarto ${ }^{15}$.

Otras preparaciones con propiedades secantes más discretas se reservan para formas menos exudativas y localizaciones específicas.

Los polvos son partículas sólidas muy finas con propiedades secantes; disminuyen la maceración y la fricción. Se usan como preventivos en áreas intertriginosas o en los pies. Están contraindicados en procesos exudativos agudos, porque, al mezclarse con las secreciones, forman grumos, que favorecen el crecimiento microbiano y la formación de granulomas. Las lociones son suspensiones 
de polvo en líquido; son secantes, protectoras, refrescantes y no engrasan; la evaporación del componente acuoso refresca la piel y tienen una ligera acción secante. Pueden usarse en lesiones agudas y subagudas. Las pastas se utilizan cuando la lesión inicial es húmeda, pero no rezuma ${ }^{15}$; son combinaciones de polvos finos (óxido de cinc, talco, almidón...) con una base grasa o acuosa; dejan una película de material pulverulento, que ejerce una función protectora y secante. El óxido de cinc es antiséptico, astringente, mejora la curación de las heridas y tiene un riesgo bajo de irritación o alergia. La pasta más utilizada es la pasta Lassar, que tiene una alta proporción de óxido de cinc en un vehículo oleoso y suma a la acción protectora del vehículo el efecto protector del óxido de cinc $^{9}$. El linimento oleocalcáreo es una emulsión de agua en aceite (w/o: water in oil) de consistencia fluida; al añadir óxido de cinc al $25 \%$, tenemos una pasta fluida, que ejerce una acción secante. La pasta al agua es una pasta acuosa que refresca y desaparece con relativa rapidez. Todas estas preparaciones no resultan adecuadas para lesiones intensamente exudativas, pero sí para el tratamiento de lesiones húmedas en zonas delicadas como los intertrigos o las dermatitis del pañal, en los que la utilización de soluciones podría resultar excesivamente secante y potencialmente irritante.

La segunda vertiente del manejo de las dermatosis exudativas será el tratamiento etiológico. Puede comenzarse tras haber controlado el componente exudativo, ya que, en general, en pocos días con las medidas adecuadas, la fase aguda va a ir cediendo. Sin embargo, en la práctica, es frecuente la aplicación paralela de ambas medidas terapéuticas. Tras retirar las compresas secantes, se puede aplicar el tratamiento tópico con el principio activo adecuado (corticoides, antibióticos, antifúngicos...). Es importante elegir el vehículo más adecuado en el que irá el principio activo. En los momentos más agudos, se recomiendan soluciones, emulsiones o geles, por su bajo contenido oleoso, pero tienen una absorción media-baja y depositan el fármaco superficialmente. Sin embargo, la utilización de cremas tiene una absorción media con poca capacidad oclusiva y son adecuadas para su utilización en procesos agudos y subagu$\operatorname{dos}^{8,9,16}$. Por supuesto, en los estados agudos de las dermatosis, pueden utilizarse conjuntamente tratamientos orales si fuese necesario, como antihistamínicos, antibióticos, antifúngicos o corticoides ${ }^{16}$.

\section{BIBLIOGRAFÍA}

1. Enta T. Practical topical therapy in dermatology. Can Fam Physician. 1982;28:1411-3.

2. Kumar V, Abbas AK, Fausto N. Inflamación aguda y crónica. En: Kumar V, Abbas AK, Fausto N (eds.). Robbins y Cotran. Patología estructural y funcional. 7.르 ed. Barcelona: Elsevier; 2005. p. 47-87.

3. Mihm MC, Kibbi AG, Wolff K. Reacciones patológicas básicas de la piel. En: Wolff K, Goldsmith LA, Gilchrest BA, Paller AS, Lefell DJ (eds.). Fitzpatrick. Dermatología en medicina general. Vol. 1. 7.a ed. Buenos Aires: Editorial Médica Panamericana; 2009. p. 43-55.

4. Alexander H, Paller AS, Traidl-Hoffmann C, Beck LA, De Benedetto $A$, Dhar $S$, et al. The role of bacterial skin infections in atopic dermatitis: expert statement and review from the International Eczema Council Skin Infection Group. Br J Dermatol. 2020;182(6):1331-42.

5. Herrera E, Sanz A, Barrera MV. Dermatitis de estasis. En: Herrera E, Moreno A, Requena L, Rodríguez Peralto JL (eds.). Dermatopatología: correlación clinicopatológica. Barcelona: Signament Edicions; 2007. p. 93-6.

6. Pereira LB. Impetigo - review. An Bras Dermatol. 2014;89(2): 293-9.

7. Rodríguez Peralto JL, Calzado L, Azorín D. Picaduras de artrópodos. En: Herrera E, Moreno A, Requena L, Rodríguez Peralto JL (eds.). Dermatopatología: correlación clinicopatológica. Barcelona: Signament Edicions; 2007. p. 500-4.

8. Habif TP. Topical therapy and topical corticosteroids. En: Habif TP. Clinical dermatology. A color guide to diagnosis and therapy. Filadelfia: Mosby; 2004. p. 23-41.

9. Casanova JM. Bases de la terapéutica dermatológica. En: Lázaro P (ed.). Pregrado. Dermatología. Vol I. Madrid: Luzán 5; 1987. p. 37-54.

10. Reeves J, Maibach HI. Soaks, baths and astringents. En: Reeves J, Maibach $\mathrm{H}$. Clinical dermatology illustrated. A regional approach. 2. ․ ed. Singapur: MacLennan \& Petty; 1991. p. 408-10.

11. Eby GA, Halcomb WW. Use of topical zinc to prevent recurrent herpes simplex infections: review of the literature and suggested protocols. Med Hypotheses. 1985;17(2):157-65.

12. Chen MX, Alexander KS, Baki G. Formulation and evaluation of antibacterial creams and gels containing metal ions for topical application. J Pharm (Cairo). 2016;2016:5754349.

13. Baker H. Diseases of the skin. Management of eczema. I. Br Med J. 1973;4(5891):544-5

14. Vicente $A$, Llambí C. Formulación magistral en dermatología pediátrica. Monografías de Dermatología. 2020;33(1):83-94.

15. Umbert $P$, Llambí F. Eccema. En: Umbert P, Llambí F. La formulación en la dermatología de 2010. 1. a ed. Madrid: Acofarma; 2008. p. 131-6.

16. Hunter JA. Diseases of the skin. The basis of skin therapy. Br Med J. 1973;4(5889):411-3. 